48. Lebkuchenkongress

\title{
Know-how für MTRA mit Tradition
}

Das zweite Adventswochenende gehört traditionell dem Lebkuchenkongress, dem Fortbildungskongress für ärztliches Assistenzpersonal in der Radiologie, Nuklearmedizin und Strahlentherapie. Am Freitag, den 6. Dezember, und Samstag, den 7. Dezember, treffen sich MTRA aus ganz Deutschland, um interessante Vorträge zu den Schwerpunktthemen „Röntgendiagnostik“, „Nuklearmedizin“ und „Strahlentherapie“ zu besuchen.

Dieses Jahr findet der Kongress bereits zum 48. Mal statt. Auch in diesem Jahr gibt es wieder die Gelegenheit, die Fortbildung zur Aktualisierung der Kenntnisse nach RöV und StrlSchV zu nutzen. Auch interessierte ärztliche Kolleginnen und Kollegen können, wie in den vergangenen Jahren, die Möglichkeit zur Fachkundeaktualisierung nutzen.

Der kulinarische Spitzname des Kongresses wurde inspiriert durch die unmittelbare Nähe zum Nürnberger Christkindlesmarkt. Dort können Sie die Fortbildungstage entspannt ausklingen lassen.

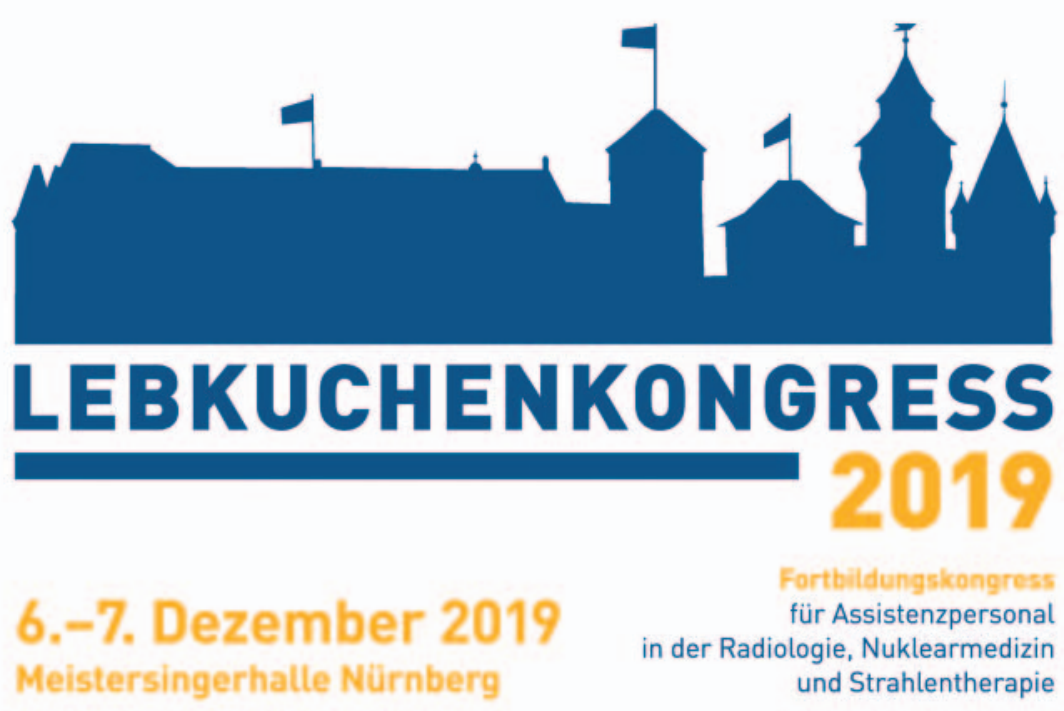

Anmelden können Sie sich ganz einfach online unter www.lebkuchenkongress.de. Wir freuen uns auf Sie in Nürnberg! Ihre DRG und VMTB mit allen wichtigen Informationen. 